Winged Ants, by infusion for forty days, provokes Lust, and helps the Gout and Palsy. 6. Liquor Formicarum. Take them cleansed, put them into a narrow-mouthed Glass, stop it, set it in brown bread in an Oven, and take it out therewith, which filter and keep for use. Inwardly it causeth magnanimity, and cures the Stone; outwardly, it helps suffusions of the eyes, cures the Itch, and dissipates Corns and Warts."

The allusion to the aphrodisiac properties of this very modest insect seems to show that Mr. Salmon (the author of this exhaustive and very interesting treatise on Pharmacology) had had some experience of the tonic properties of formic acid. The mention of the morally tonic effect of this drug in Mr. Mackintosh's letter makes Salmon's observation $r e$ the magnanimity caused by a dose of liquor formicarum very interesting. As regards the immunity possessed by ant eaters, to the effect of the formic acid they are constantly imbibing, would it not be a matter of surprise if they had not become habituated to the drug? If they were deprived of their daily dose it is to be reasonably expected that they would suffer in much the same way as the habitual user of any other stimulant. The picture drawn of the ant-eater by Mr. Mackintosh would stand very well for the human habitué of stimulants. Other insectivora such as the armadillo, not living exclusively upon ants, are lively enough. I am, Sirs, yours faithfully,

Liverpool, Dec. 6th, 1907.

H. G. HigGins.

\section{THE TUBERCULIN OPHTHALMIC REACTION.}

To the Editors of THE LANCET.

Sirs,-A good deal of discussion will probably take place in your columns about the reliability of Calmette's tuberculin test, and I await with considerable interest the result of the tests now being carried out at the London Hospital. That it is not infallible I have already found in a small series of cases tested during the past six weeks. I have found three cases of pulmonary tuberculosis where Roentgen examination demonstrated extensive mischief (on case was tested on two occasions) and where tubercle bacilli were found in the sputum, which did not react in the slightest to this test, but I have also found some very early cases give a sharp reaction. On the other hand, the diagnosis of a swelling in the neck of a patient aged 48 was much simplified by a very sharp reaction, and when opened the pus was found to contain tubercle bacilli. An ulcer on the chin of a child aged ten, which appeared to be of a tuber culous nature, and which had resisted treatment for three years, was tested and gave no reaction and eventually proved to be non-tuberculous and was cured by the extraction of a carions lower molar. Three out of four cases of lupus erythematosus gave a very sharp reaction, and the fourth case was certainly not active; a case of lupus vulgaris which had been cured by the $x$ rays gave no reaction. Two cases of enlarged cervical glands in children likewise gave no reaction and proved to be non-tuberculous. These are a few out of a series of 50 cases taken haphazard; the reaction in some cases has commenced as soon as from five to seven hours after the drop of tuberculin was instilled into the eye, but in the majority of cases the onset of redness was delayed until the sixteenth to twentieth hour; in one case the eye was inflamed for more than a week.

Lincoln, Dec. 4th, 1907.

$$
\text { I am, Sirs, yours faithfully, }
$$
Stanley GReen.

\section{PULMONARY REGURGITATION.}

7 o the Editors of THE LANCET.

SIRS,-It would add a fresh terror to recording clini ca experiences were we expected to refer to all previous work on the same lines. It is therefore without any sense of surprise that $I$ find Professor T. Oliver, among the references he makes to the literature of the subject on which he treats in THE LANCET of Dec.7th, does not mention my own published experience of pulmonary valvular disease. Indeed, I should not draw attention to it now were it not that I covered much of the ground he has traversed from a diagnostic point of view, and my case, like his, presented some features of especial interest at present to which I shall refer immediately.

In 1879-80 I published in the Edinburgh Medical Journat a paper on dextral valvular disease of the heart in which an accurate drawing of a well-marked case of ulcerative endo. carditis involving the pulmonary valves will be found, together with a collection of cases at that time conveniently accessible and in which I discussed the mechanics of the whole matter rather fully. The more important reason for which I refer to the subject now is that Professor Oliver's case, like my own, exhibited a point of considerable physiological interest to us at the present moment. I refer to the fact that the septum of the heart in his case was ploughed up by an aneurysm which opened into the right ventricle "almost immediately under the valves of the pulmonary artery." Notwithstanding this there seems to have been no marked dissociation of the regular sequence of auricular and ventricular contraction.

In my case the ulcerative process had destroyed what we now regard as the point of transit of the "bundle of His" from the right into the left ventricle but without disordering the normal cardiac rhythm. I hope the heart of Professor Oliver's case has been preserved and that some expert anatomist, like Professor A. Keith, may have an opportunity of determining the /condition of the A.V. bundle, of which we have heard and learned a good deal of late. My own specimen, which I presented to the museum of the hoyal College of Physicians in Edinburgh, has, I fear, been lost Like Professor Oliver's, my case, moreover, also evinced cardiac pain and in mine the radiation of the pain was very distinctly down the right arm, a point of interest in the circumstances, it will be conceded, as throwing some light on the essentially and necessarily neural cause of the pain in angina pectoris.-I am, Sirs, yours faithfully,

Upper Berkeley-street, W., Dec. 7th, 1907. ALexander Morison.

\section{THE REFORM OF THE ROYAL COLLEGE OF SURGEONS OF ENGLAND.

$$
\text { To the Editors of THE LANCET. }
$$

Sirs,-I am glad to see Mr. Samuel Knaggs's temperate contribution to the discussion of this question, although I am one of those who "think differently" from him. He uses one of the most principal arguments placed before the Lord President by the College Council-viz., that the best Members would not stand in case of an election and that the seats would be taken by "plausible agitators." As one of the latter I would say that our opinion is exactly to the contrary. We are convinced that the best Members would come forward, if they were sure of a welcome by the Council. Moreover, I, and no doubt any others objected to, would be perfectly willing to stand aside and to allow others to reap where we have sown, if this would in any way facilitate the reform. It is no secret that the main objection on the part of the Council is a personal one and this can be very easily removed in the above manner. The best Fellows have always come forward for election, why should not the best Members do so ?-I am, Sirs, yours faithfully,

Putney, Dec. 8th, 1907. W. G. DICKINSON.

\section{MEDICAL INSPECTION OF SCHOOL CHILDREN.}

To the Editurs of THE LANCET.

SIRs, - As a member of the public health service I have, of course, read your leading article of Nov. 30th and the memorandum of the Board of Education with the greatest interest. The former is a scorpion, inasmuch as the sting lies in the tail or last sentence. I suppose this was added to balance the expression "a well-conceived pronouncement" at the beginning of your last paragraph. However, your attitude is a refreshing contrast to that of one of your contemporaries. At the beginning of your article you state, "Upon him (i.e., the medical officer of health) will devolve the loral organisation of such assistants as he deems necessary," and towards the end, "the placing of the work of medical inspection entirely sets aside the discretion of the education authority in the matter of appointments." I cannot find anything in the memorandum to justify these statements of THE LANCET; I wish I could. I agree that as the medical officer of health has to supervise the work of any assistants he may have he should have at least a voice in their selection. It is a pity that on page 6 of the memo. randum it is not made clear who shall be the judge of whether "the work is obviously more than he can undertake anaided."-I am, Sirs, yours faithfully,

Dec. 3rd, 1907.
A NORTH LONDON M.O.H 